\title{
Low molecular weight varnishes. Interview to E. René de la Rie, National Gallery of Art, Washington, DC.
}

\author{
Ruth Chercoles, Benoît de Tapol, Ana Ordoñez and Lourdes Domedel
}

René de la Rie has been working since 20 years on Low Molecular Resins. In February, 2011 a technical Workshop took place, organized by GEIIC (Spanish group of International Institute of Conservation) in the Reina Sofia Museum. René de la Rie, Ana Ordoñez and Lourdes Domedel were the speakers and presented the results of the research they carried out. Questions that arose at this meeting are addressed in this interview.

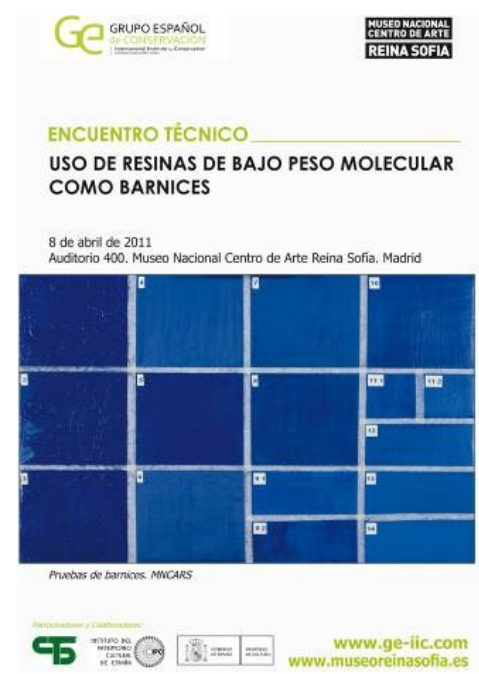

Biography of René de la Rie

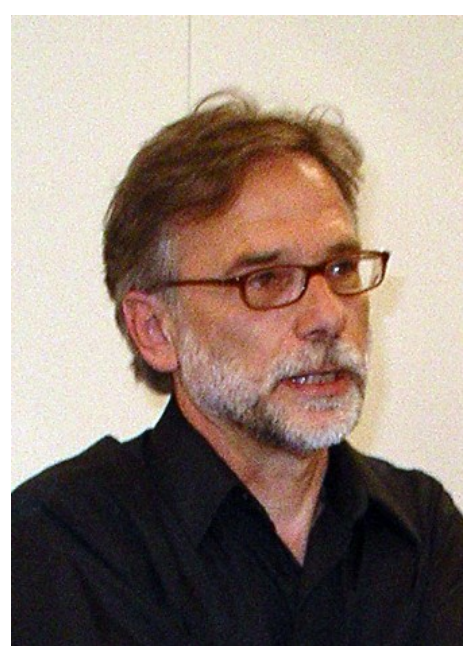

E. René de la Rie Author: Marisa Gómez. r-delarie@nga.gov
E. René de la Rie is head of scientific research at the National Gallery of Art, Washington, DC, a position he has held since 1989 and which is endowed by the Andrew W. Mellon Foundation. He holds a doctorate in chemistry from the University of Amsterdam, The Netherlands and previously held positions at the Metropolitan Museum of Art, New York, and at the Training Program for Conservators and the Central Research Laboratory for Objects of Art and Science (now ICN), both in Amsterdam. He has also held adjunct positions at the University of New York and the University of Amsterdam and served as Ph.D. advisor at the latter institution. He was an editor for the journal Studies in Conservation from 1994 until 2011.

The scientific research department's staff studies the methods and materials used by artists and conservators, using advanced analytical instrumentation. The department regularly hosts research fellows, several of whom have taken up positions in museums. 


\section{Interview}

\section{General Questions:}

\section{What was your motivation to start working on resins with low molecular weight (LMW)?}

The goal of the research was to develop new varnishes with optical properties similar to those of the natural varnishes but with much greater stability. The research involved a search for new resins, either by synthesizing them or by sourcing them from industry, and study of the degradation process, the effects of stabilizers and the factors that affect optical properties. The latter showed that low molecular weight is required to obtain optical properties similar to those of the natural resins.

You have been working on LMW resins for many years. When did you start and when did you stop working on it? Why?

The research was started at the Metropolitan Museum of Art in the 1980s. The work was continued at the National Gallery of Art in the 1990s and 2000s. We never really stopped (articles on the optical aspects were published recently). But the main questions have been answered. The optical issue is understood now, stable resins with the right properties are available and used by many conservators, and the effects of stabilizing additives have been demonstrated. There is always more to be done and we still have a few studies going on that will be published eventually.

For this kind of investigation, do you recommend to be connected with industry, as you did with $B A S F$ ? Could you explain why?

Yes, collaboration with industry (as well as with academia) is fundamental in this kind of research. There is tremendous expertise outside the conservation field that can be tapped into and materials may be available that have not been considered for use in conservation and may have useful applications.

What kind of recommendation will you suggest in case of a partnership between conservators or chemists and industry, to deal with this kind of project?

Industry in my experience is interested in this kind of work if you ask the right questions. They will in general not be able to solve the problems for you, but they may make products and expertise available.

Did you develop applications of LMW varnish for other fields than painting, like protection of metal, paper, etc.?

The work was done primarily with paintings in mind but these resins can be used in any application where natural resins are used. I know that some have used them on furniture and on metal objects.

Nowadays you are working in Paris in the field of paper. What are the main objectives of your work?

The National Gallery of Art and the Centre de Recherche sur la Conservation des Collections (CRCC) in Paris are involved in collaborative research into reactions at the wet-dry interface in paper. These reactions lead to colored and fluorescent tidelines. The work has relevance for local wet treatments of cultural objects on paper. The goal is to understand the phenomena and to find ways to inhibit them. 
Have you worked with scientists and conservators from other institutions? Do you know if they work usually with $L M W$ varnishes, as alternatives to traditional ones?

Collaboration with scientists and conservators from other institutions has been essential to this research. We have also conducted many workshops in collaboration with conservators in which the research is presented alongside practical sessions. Many conservators from other institutions now use synthetic low molecular weight resins for varnishing and retouching.

Following the characteristics that have been pointed out for a good varnish, we selected several questions related to: stability, optical aspects and workability.

\section{About Stability:}

Some LMW varnishes are diluted in aromatic solvent (medium level of retention) or in aliphatic solvent (Turpentine very high level of retention).Do you think it is acceptable regards to leaching phenomena?

Aromatic content is not really related to solvent retention. Aromatic content and chemical composition in general determine the overall polarity of the solvent and its ability to dissolve materials. Solvent retention is controlled by evaporation rate and diffusion rate. Regalrez 1094 does not require an aromatic solvent. It dissolves in a 100\% aliphatic solvent. Laropal A81 requires 30-40\% aromatics. In theory, higher aromatic solvents could cause more leaching but we believe that the aromatic content required for Laropal A81 is acceptable. It is still a solvent mixture with much lower polarity than those typically used for cleaning. Turpentine should not be used for synthetic LMW varnishes. Many conservators find that an aliphatic solvent with relatively fast evaporation, such as Shellsol D40, works well for brush application of Regalrez 1094. Solvents that evaporate even faster may be used for spray application. Slower hydrocarbon solvents may be retained longer by hydrocarbon resins such as Regalrez 1094 because of their mutual affinity.

During the restoration process, application of successive layers of traditional varnishes can create stress in multilayer paintings that are poorly bounded. It is not well known but this phenomenon should guide restorers to limit the use of multilayers of concentrated varnish at the surface of the painting. Are $L M W$ solving this problem? Is there a relation between glass transition temperature (Tg) and strength?

Do you think that conservators, who are dealing with very fragile paint layer, should take into consideration these criteria when chosing a varnish?

A varnish does not need to be terribly strong (Gary Thomson [1] argued many years ago that it should be the weakest layer in a painting). A fragile paint layer could be damaged by a strong varnish. Fragile paint may have to be consolidated but that is better dealt with in a separate treatment. Low molecular weight resins, including the natural ones, have relatively high glass transition temperatures and are relatively brittle. They are therefore not likely to cause much stress in underlying paint layers. Some are more brittle than others - MS2A is more brittle than most and it should be kept in mind that the brittleness of natural resins increases dramatically with aging. 


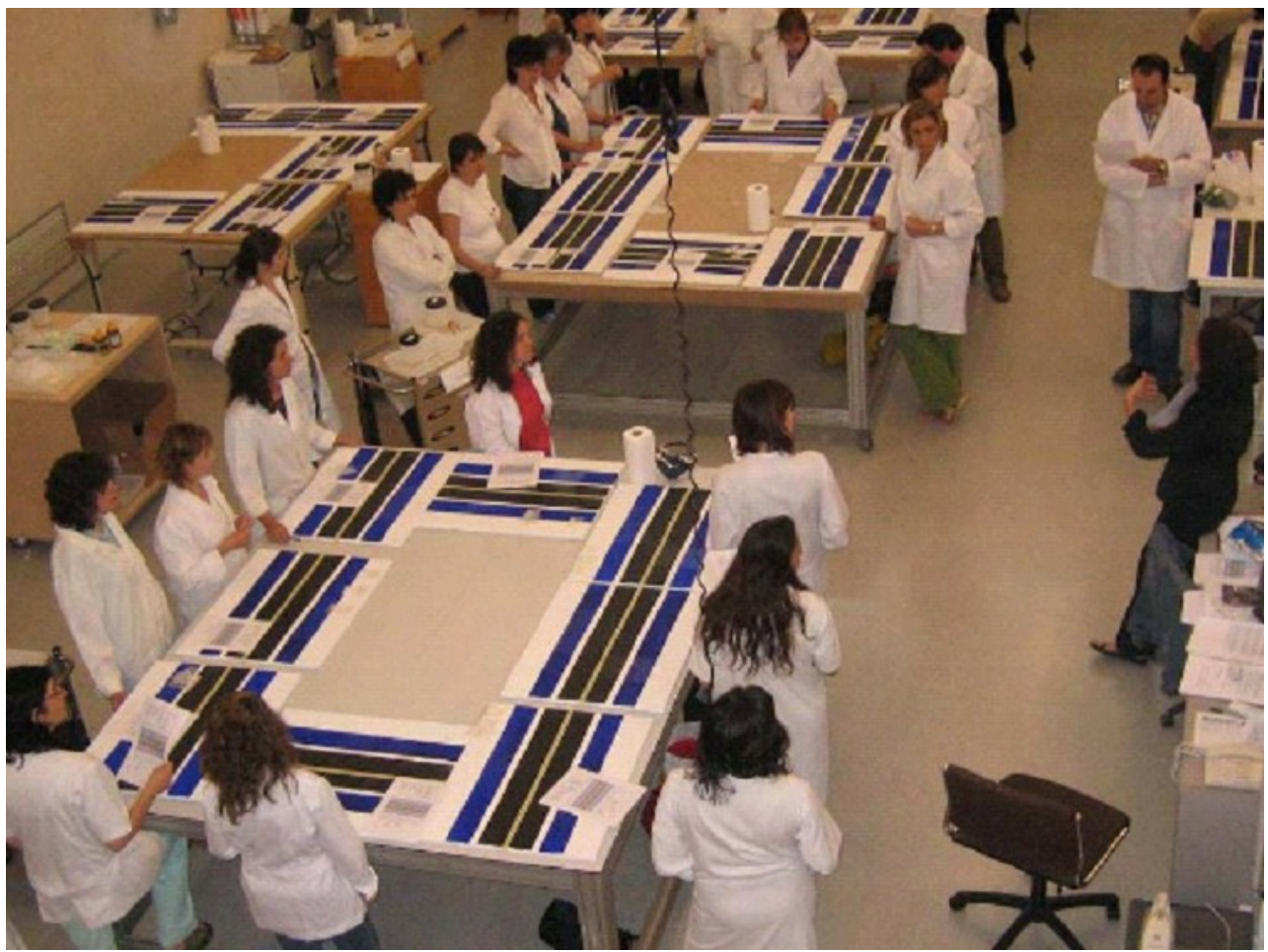

Figure 1. Picture taken in the Conference Evolution of varnishes applied in conservation and restauration of fine arts. Barcelona 2006. Author: Marisa Gómez.

For maximum stability a hindered amine light stabilizer (HALS), like Tinuvin 292, should be added. How long does Tinuvin $292 \mathrm{keep}$ in the bottle without degradation? How long does it keep in a good state of conservation when it is mixed with varnish in the bottle? How long does the varnish with Tinuvin 292 last once it has been applied to the painting?

Tinuvin 292 should indeed be added, as it prolongs the lifetime of varnishes dramatically. We have found that it is stable by itself for a number of years but I recommend not using it when it is more than a few years old. When mixed in with varnish in solution it is best to not keep it too long. My recommendation is to prepare small quantities and to not keep these for more than a few weeks.

Hindered amine light stabilizers (HALS) act by interfering with oxidation reactions. By incorporating HALS a much more stable system is obtained. Our accelerated aging experiments indicate that the lifetime is extended greatly. By how much in real life can only be found out after many years. Monitoring of natural aging so far indicates that the stabilizer works as predicted by accelerated aging. It has to be kept in mind that dammar can only be stabilized in the absence of UV.

Tinuvin 292 is known to stabilize in the presence of $U V$ light, but in museums nowadays there is no UV light at all, but only visible light. Is Tinuvin useful in those cases?

Tinuvin 292 only works in dammar resin in the absence of UV light, so in those museum environments addition of the HALS to dammar makes perfect sense. We have an ongoing study of the aging of synthetic low molecular weight resins in an environment without UV and this work will eventually be published. Regardless, I highly recommend adding the stabilizer even if there is no UV, as it is a simple thing to do and it may prolong the life of the varnish even without UV. 
Does Paraloid B-72 function as a barrier against oxidation of a natural resin if it is used on top of it? Do LMW varnishes act also as good barriers?

No, Paraloid B-72 does not significantly prevent oxidation of lower layers. Neither do any of the other resins typically used for varnishing. Diffusion of oxygen is fairly rapid through these thin layers and they also do not prevent UV and visible light from reaching the lower layer. Photooxidation of lower layers is therefore not significantly inhibited by a top varnish. As I point out in my lectures, varnishes in general provide little protection and should not be applied for that reason. Their primary function is aesthetic.

Is Paraloid B-72, applied on stone and exposed to the open air, biodegradable? Do you think it is the same thing once it is applied on painted surfaces? Under which conditions will it be modified?

I am not an expert on biodeterioration but I know that many resins are biodegradable and Paraloid B-72 is probably among them. Biodegradation is probably more of an issue outdoors and in unclimatized indoor environments than in museum environments. B-72 is otherwise one of the most stable materials around.

In case of using a superposition of 2 varnishes, are there any interactions between these two coats of varnishes (LMW resins on the top of Dammar)? If so, what are they?

Whether varnish layers interact depends on their solubilities. Regalrez 1094 dissolved in an aliphatic solvent should not interact significantly with a lower layer. If a more polar solvent is required for the top varnish, resolubilization of the lower layer may occur. Again, keep in mind that a top layer does not provide much protection for an underlying layer.

\section{Should both coats contain Tinuvin or it is sufficient if it is only on the top coat?}

Tinuvin 292 should be added to both layers, as the top layer does not provide much protection for the lower layer. Keep in mind though that dammar can only be stabilized in the absence of UV.

Can $L M W$ vanishes be used as a consolidant in mural painting? Does alkalinity of chalk in mural painting have any influence on durability of the $L M W$ varnish?

Although synthetic low molecular weight resins may be used in consolidants, additional ingredients are likely necessary to obtain the required properties. This is actually a subject of current research at the National Gallery of Art. I don't think chalk will have an adverse effect on the resins.

\section{About Optical Properties:}

According to other investigations, MS2A (chemically reduced ketone resin) provides an optical aspect that is much more matte than Dammar resin, and Laropal A81 has higher gloss, Do you agree with this?

MS2A may give somewhat lower gloss, but the appearance obtained with any of these resins depends on many factors, such as concentration, type of solvent and application method. All low molecular weight resins potentially can produce high gloss, but low gloss and even a matte appearance can be obtained with all of them. 


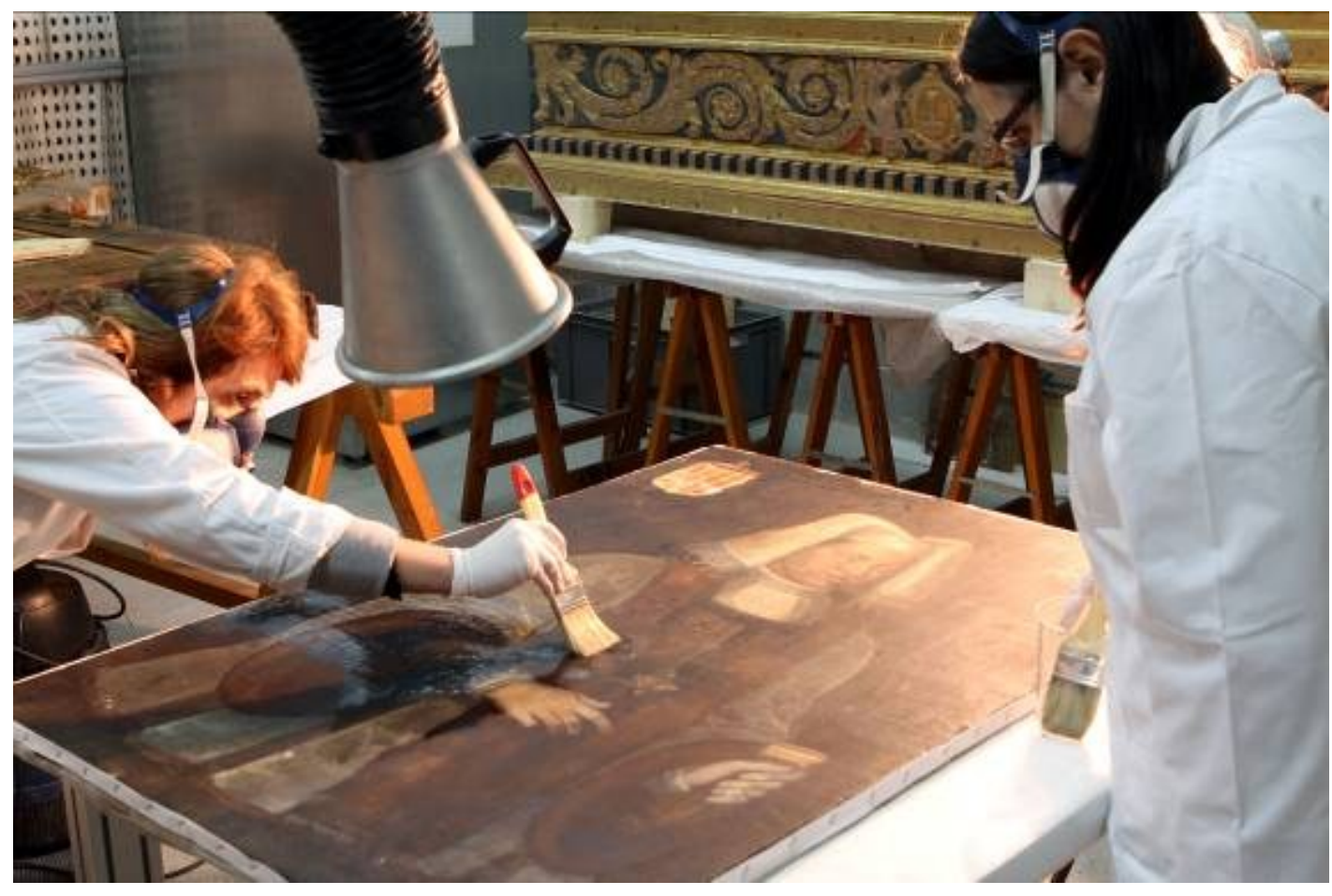

Figure 2. Low molecular resin applied by brush. Authors: Ana Ordoñez and Lourdes Domedel

\section{How can one modify $L M W$ resins to have a matte appearance?}

A lower gloss appearance may be obtained more easily with a polymeric resin, such as Paraloid B-72. A matte appearance may be obtained with a low molecular weight resin at low concentration, by using a fast evaporating solvent and by spraying instead of brushing. Additives such as wax may also be used but it is my understanding that this doesn't always work. These issues are better addressed by practicing conservators who have experience in using these resins.

What are the optical effects produced between varnishes if we apply a first coat by brush and a second with a paint gun?

A sprayed varnish may produce lower gloss due to loss of solvent from droplets before they hit the surface, resulting in incomplete leveling at the no flow point. The appearance again depends on many factors.

The LMW varnishes improve the optical properties of the surface, because of its decrease of shrinkage, but the problem is the absorbance in a porous substrate. So, do you recommend varnishing first with a natural or synthetic varnish, to increase impermeability, and on top, apply the $L M W$ resin?

Some conservators seal a porous surface first with a polymeric resin such as Paraloid B-72. I would not recommend using dammar for that purpose because of its instability and besides it may sink in too.

If we try to equalize the gloss with a dry brush, do you think that this operation is correct, in a sense of durability, micro abrasions etc.

I don't think brushing has any affect on durability. 


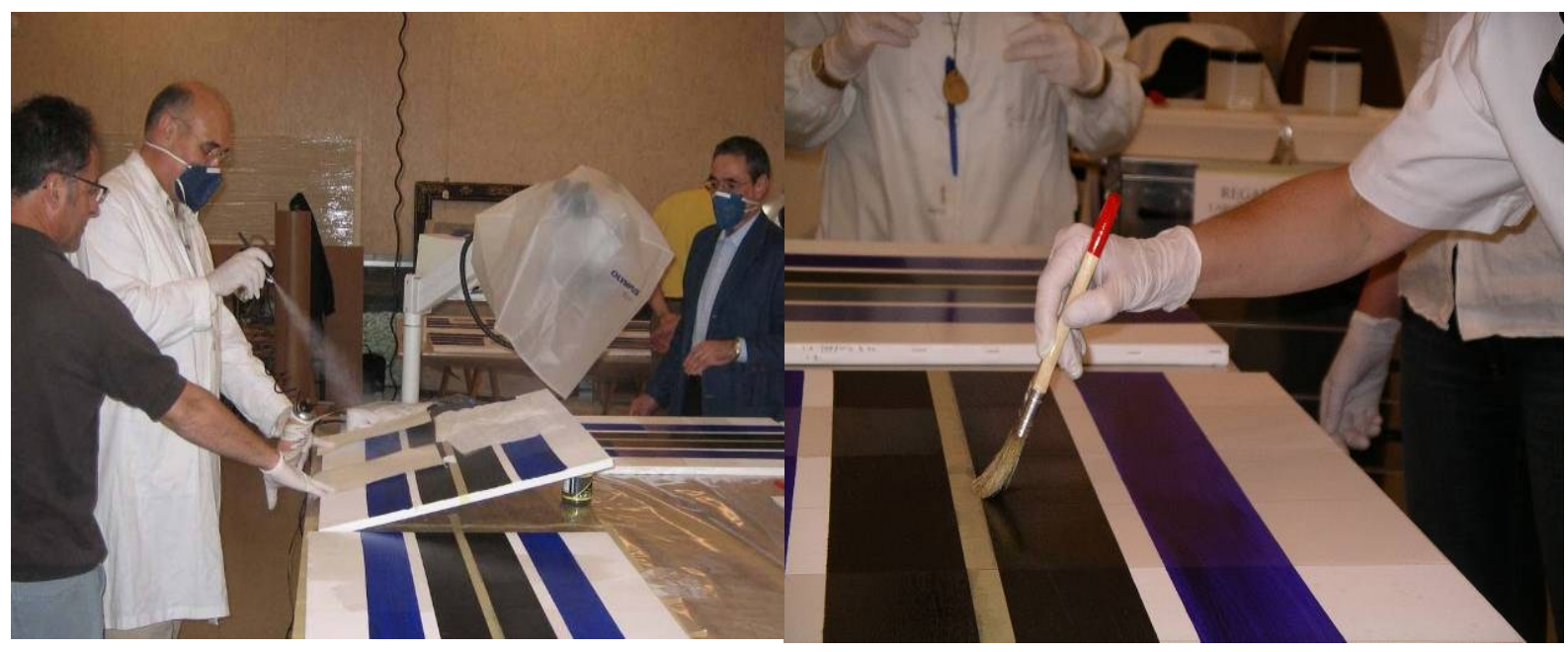

Figures 3. $\mathbf{a}$ and $\mathbf{b}$ :. Varnishes applied by brush or spray gun. Picture taken in the Conference Evolution of varnishes applied in conservation and restauration of fine arts. Barcelona 2006. Author: Marisa Gómez.

\section{About Workability:}

A number of the questions regarding working properties above and below have to do with practical use of the resins and would be better addressed in practical sessions with conservators who have experience using them. There are many tricks of the trade. We have found in our workshops that conservators generally have much greater success with the resins after learning what concentrations to use, what solvents to use and how to apply them. It is highly recommended that those who are having trouble using these resins contact conservators who have success with them or try to attend a workshop.

\section{With LMW vanishes do you recommend using a paint gun for varnishing a painting on panel?}

All varnishes can be applied either by brush or spray gun.

It's very difficult to work with a dry brush at the surface recently varnished with a $L M W$. The evaporation of the solvent is so quick, and you can't really equalize the surface. Is there an alternative way of application to correct this problem?

This depends on the evaporation rate of the solvent. By using a solvent with a lower evaporation rate one obtains a longer work time.

In adverse conditions of conservation, like uncontrolled climate, polluted and dusty environment (churches, cloisters, building close to the main traffic road etc.), do you recommend a special varnish or way to apply it (concentration, method...)?

Stable varnishes are recommended in any environment but in particular in uncontrolled climates.

If a conservator decides to use a $L M W$ as a varnish and pigments with $L M W$ resin as a retouch product, they can't apply the varnish on top of the retouched areas with brush isn't?

It depends on which resins are used. If the paint contains Laropal A81 as a binder (as in the Gamblin paints) and the varnish is Regalrez 1094, then there are no re-solubilization issues. 
Pigments mixed with varnish had been used in the past as a retouch product, Dammar or Paraloid B-72 with pigments. Do you think it is better to use a prepared mixture in a jar (like Gamblin) or is it better to mix the two products with a solvent at the last moment, handmade and a fresh dispersion, to have a better result?

The Gamblin paints were developed as a replacement for natural resin retouching paints. Having Laropal A81 as a binder, they are stable and can produce optical effects similar to natural resin paints. They have the additional benefit of being produced using a professional three-roll mill. This gives better pigment dispersion than can be obtained by hand and hence they have very good working properties.

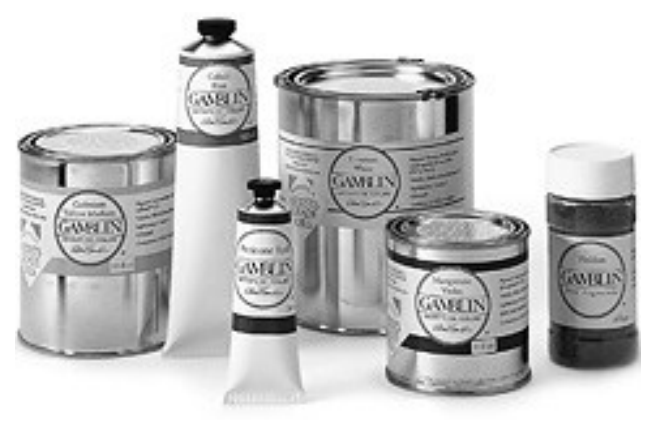

Figure 4. Gamblin paints and mediums. Gamblin artist colors

\section{Is there something that you want to add as conclusion or comment not expressed in the questions? Or a comment regarding the workshop in Madrid?}

A number of comments were made during the discussion after my lecture in Madrid that appeared to indicate confusion regarding the optical experiments on glass in relation to the penetration issue. It is perhaps important to point out that these are two entirely different issues. The experiments using glass substrates demonstrated that low molecular weight resins level to a greater extent over microscopically rough surfaces than polymeric resins, and hence have the potential of providing higher gloss and greater color saturation. Varnishes made with low molecular weight resins, which includes the natural resins, have relatively low viscosities and therefore may penetrate porous surfaces to a greater extent. Many conservators have found ways to work with the resins, even on relatively porous surfaces, but to prevent sinking in, a polymeric varnish such as Paraloid B-72 may be applied first or a polymer can be added to the low molecular weight resin to increase the viscosity. This was the reason we tested Kraton Rubbers as additives for Regalrez 1094, but not everyone feels that they are necessary. Laropal A81 solutions have higher viscosity than those of Regalrez 1094 and therefore may not sink in as easily. Again, it should be kept in mind that natural resin solutions also have relatively low viscosities and may sink in significantly.

\section{Notes}

[1] Garry Thomson (13 September 1925 - 23 May 2007) began his career as a Research Chemist, at the National Gallery (London), a post he held from 1955 to 1960, when he was promoted to Scientific Adviser to the Trustees and Head of the Scientific Department at the National Gallery from 1960 a post he held until his retirement in 1985. In 1968 Garry organized the first conference on museum climatology for the International Institute for Conservation (IIC) in London. He also served as President of the International Institute for Conservation (IIC), from 1983 to 1986. He undertook various missions for ICCROM, including to Algeria, India and Lebanon. With colleagues, he conceived the ICCROM course on 'Scientific Principles of Conservation', which was launched in Rome in 1974, and in which he also taught. In 1976 he contributed to the new ICCROM course on 'Preventive Conservation' and was a regular lecturer at 
ICCROM until 1989. Following his retirement he was a trustee of the National Museums and Galleries on Merseyside from 1986 to 1991. In 1999 he received the first Plowden Gold Medal, awarded by the Royal Warrant Holders' Association to recognise the most significant contributions to the advancement of the conservation profession

\section{Bibliography}

DE LA RIE, E. R. (1988)."Polymer Stabilizers. A Survey with Reference to Possible Applications in the Conservation Field". Studies in Conservation 33: 9-22.

DE LA RIE, E. R., and McGlinchey, Ch. (1989). "Stabilized Dammar Picture Varnish." Studies in Conservation 34. 137-146.

DE LA RIE, E. R. (1989). "Old Master Paintings: A Study of the Varnish Problem." Analytical Chemistry 61: 1228A$1240 \mathrm{~A}$.

DE LA RIE, E. R., and MCGLINCHEY, CH. (1990). "New Synthetic Resins for Picture Varnishes." In Cleaning Retouching and Coatings, IIC 1990 Brussels Congress, edited by John S. Mills and Perry Smith, London: International Institute for Conservation of Historic and Artistic Works (IIC), 168-173

DE LA RIE, E. RENÉ, AND MCGLINCHEY, CH. (1990). "The Effect of a Hindered Amine Light Stabilizer on the Aging of Dammar and Mastic Varnish in an Environment Free of Ultraviolet Light". In Cleaning Retouching and Coatings, IIC 1990 Brussels Congress, edited by John S. Mills and Perry Smith. London: International Institute for Conservation of Historic and Artistic Works (IIC), 160-164.

DE LA RIE, E. R. (1991). "Degradation and Stabilization of Varnishes for Paintings." In Preprints to the Thirteenth International Conference on Advances in the Stabilization and Degradation of Polymers. Lucerne, 129-139.

DE LA RIE, E. R. (1992). "Stability and Function of Coatings Used in Conservation." In Polymers in Conservation, edited by N. S. Allen, M. Edge, and C. V. Horie. Cambridge: Royal Society of Chemistry, 62-81.

DE LA RIE, E. R. (1993). "Polymer Additives for Synthetic Low-molecular-weight Varnishes". In Preprints of the 10th Triennial Meeting of the ICOM Committee for Conservation, Washington DC, edited by Janet Bridgland,. Paris: ICOM Committee for Conservation, 566-573.

DE LA RIE, E. R. (1999). "Conservation Science Unvarnished. Oration delivered on the assumption of the special chair for the Chemistry of Conservation and Restoration at the University of Amsterdam on 30 October 1997." Amsterdam: Stichting Bijzondere Leerstoel voor de Chemie van Conservering en Restauratie.

DE LA RIE, E. R., QUILLEN LOMAX, S., R. PALMER, M., DEMING GLINSMAN, L., and A. MAINES.C. (2000). "An Investigation of the Photochemical Stability of Urea-aldehyde Resin Retouching Paints: Removability Tests and Colour Spectroscopy." In Tradition and Innovation: Advances in Conservation, IIC 2000 Melbourne Congress, edited by Ashok Roy and Perry Smith. London: International Institute for Conservation of Historic and Artistic Works (IIC), 51-59.

LEONARD, M., WHITTEN, J., GAMBLIN, R., and DE LA RIE. E.R. (2000). "Development of a New Material for Retouching" In Tradition and Innovation: Advances in Conservation, IIC 2000 Melbourne Congress, edited by Ashok Roy, and Perry Smith. London: International Institute for Conservation of Historic and Artistic Works (IIC), 29-33.

BERNS, R.S., and DE LA RIE. E. R. (2001)."Evaluating the Effect of Varnishes on the Color and Spatial Image Quality of Paintings." In PICS 2001: Image Processing, Image Quality, Image Capture Systems Conference, Montreal. Springfield VA: Society of Imaging Science and Technology (IS\&T), 181-184.

BERNS, R.S., and DE LA RIE, E. R. (2002). " The Relative Importance of Surface Roughness and Refractive Index in the Effects of Varnishes on the Appearance of Paintings." In Preprints of the 13th Triennial Meeting of the ICOM Committee for Conservation, Rio de Janeiro, September 2002, vol. 1, edited by Roy Vontobel. London: James and James (Science Publishers) Ltd., 211-216. 
DE LA RIE, E. R., QUILLEN LOMAX, S., PALMER, M. R., and MAINES, CH. A. "An Investigation of the Photochemical Stability of Films of the Urea-Aldehyde Resins Laropal ${ }^{\circledR}$ A 81 and Laropal ${ }^{\circledR}$ A 101." In 13th Triennial Meeting of the ICOM Committee for Conservation, Rio de Janeiro, September 2002, vol. 2, edited by Roy Vontobel. London: James and James (Science Publishers) Ltd.: 881-887

BERNS, ROY S., and DE LA RIE. E. R. (2002). "The Effect of a Varnish's Refractive Index on the Appearance of Oil Paintings." Studies in Conservation 48, 251-262.

BERNS, R.S., and DE LA RIE. E. R (2003). "A Methodology for Analyzing the Effect of Varnishes on the Appearance of Paintings." Studies in Conservation 48 : 73-82.

DE LA RIE, E. R. (2003). "Why Use a Synthetic Picture Varnish?" In Art et chimie, les polymères, edited by Jean-Claude Bernier, François Guinot, Jean-Pierre Mohen, and Pierre Potier, 63-68. Paris: Centre national de la recherche scientifique (CNRS).

MAINES, CH. A., and DE LA RIE, E. R. (2005). "Size-exclusion Chromatography and Differential Scanning Calorimetry of Low Molecular Weight Resins Used as Varnishes for Paintings." Progress in Organic Coatings 52: 39-45.

MADY, E., DE LA RIE E. R., DELANEY, J. K. CHARRON, E., and MORALES, K. M. (2006). "Modification of the Surface State of Rough Substrates by Two Different Varnishes and Influence on the Reflected Light." Optics Communications 266: 586-591.

DELANEY, J. K., DE LA RIE E. R., MADY, E., LI-PIIN SUNG, and MORALES, K. M (2008). "The Role of Varnishes in Modifying Light Reflection from Rough Paint Surfaces. A Study of Changes in Light Scattering Caused by Variations in Varnish Topography and Development of a Drying Model." Studies in Conservation 53: 170-186.

MADY, E., DE LA RIE E. R., and DELANEY, J. K. (2008). "Modification de l'etat de surface et de l'apparence visuelle de surfaces rugueuses recouvertes par différents vernis." In De la peinture de chevalet à l'instrument de musique: vernis, liants et couleurs. March 6-7, 2007, edited by Nadine Ballot, 122-128. Paris: Cité de la musique.

DE LA RIE E. R., DELANEY, J. K., MORALES, K. M., MAINES, CH. A., and LI-PIIN SUNG (2010). "Modification of Surface Roughness by Various Varnishes and Effect on Light Reflection." Studies in Conservation 55: 134-143.

\section{Ruth Chércoles Asensio}

Chemist.Universidad Complutense de Madrid- IPCE ruthchercoles@yahoo.es

\section{Benoît de Tapol}

Servicio Científico-técnico del Departamento de

Restauración y Conservación Preventiva del

Museu Nacional d'Art de Catalunya

benoit.detapol@mnac.cat

\section{Ana Ordoñez}

Centre de Restauració de Béns Mobles de Catalunya anaordonyez@hotmail.com

\section{Lourdes Domedel}

Centre de Restauració de Béns Mobles de Catalunya louloudp@gmail.com 